\title{
New insights in the pathology of peritoneal surface malignancy
}

\author{
Norman John Carr \\ Peritoneal Malignancy Institute, Basingstoke and North Hampshire Hospital, Basingstoke, UK \\ Correspondence to: Norman John Carr, FRCPath. Peritoneal Malignancy Institute, Department of Histopathology, Basingstoke and North Hampshire \\ Hospital, Aldermaston Road, Basingstoke, RG24 9NA, UK. Email: Norman.carr@hhft.nhs.uk.
}

\begin{abstract}
Pathology is central to the management of peritoneal surface malignancy. This article highlights some recent advances that have had an impact on patient management or could do so in the near future. Malignant peritoneal mesothelioma, particularly the epithelioid subtype, is amenable to radical therapy in selected cases, and factors such as ki67 proliferation index, expression of BAP1 and mutation in CDKN2A show promise as prognostic indicators. Our understanding of multicystic mesothelioma has improved in recent years; it is a true neoplasm for which surgery may be indicated. Serous carcinomas involving the peritoneum are now known to originate from tubal epithelium. They are of two distinct types, high grade and low grade, which are now recognized as different neoplasms with distinctive features, oncogenesis and behavior. Pseudomyxoma peritonei (PMP) is an unusual condition that usually arises from an appendiceal mucinous neoplasm. Recent consensus in the classification and nomenclature of these lesions is discussed, including the distinction between low grade and high grade appendiceal mucinous neoplasms (HAMN), and the diagnostic criteria for appendiceal adenocarcinoma. PMP is divided into four prognostic groups: acellular mucin, low grade mucinous carcinoma peritonei, high grade mucinous carcinoma peritonei, and high grade mucinous carcinoma peritonei with signet ring cells. The pseudomyxoma microbiome is a promising area for clinical intervention but has been the subject of little research activity. Goblet cell adenocarcinoma (previously known as 'goblet cell carcinoid') is a distinctive type of appendiceal adenocarcinoma. Its behavior correlates with histologic features, but no general consensus for classification has been reached.
\end{abstract}

Keywords: Appendiceal neoplasms; peritoneal neoplasms; pseudomyxoma peritonei (PMP); mesothelioma; serous carcinoma

Submitted Mar 18, 2020. Accepted for publication Jun 08, 2020.

doi: 10.21037/jgo-2020-01

View this article at: http://dx.doi.org/10.21037/jgo-2020-01

These are exciting times in the pathology of peritoneal surface malignancy. On one hand, the management of patients depends increasingly on accurate pathologic classification and the identification of prognostic and predictive factors. On the other hand, scientific advances are leading to new insights in the genetics and oncogenesis of these lesions. Pathology is central to concept of personalised medicine, which in some cases already has a role in treatment. This article highlights some areas in which recent advances have had an impact on patient management or have the prospect of doing so in the near future.

\section{Prognostic and predictive factors in peritoneal malignant mesothelioma}

Malignant mesothelioma of the peritoneum has traditionally been associated with a dismal prognosis. However, studies have shown that cytoreductive surgery (CRS) combined with heated intraperitoneal chemotherapy (HIPEC) represents effective treatment in selected cases, and there is consequently a need for markers that could predict response to such treatment. Differences between pleural and peritoneal mesotheliomas suggest that we cannot simply extrapolate findings from pleural tumors and apply them 


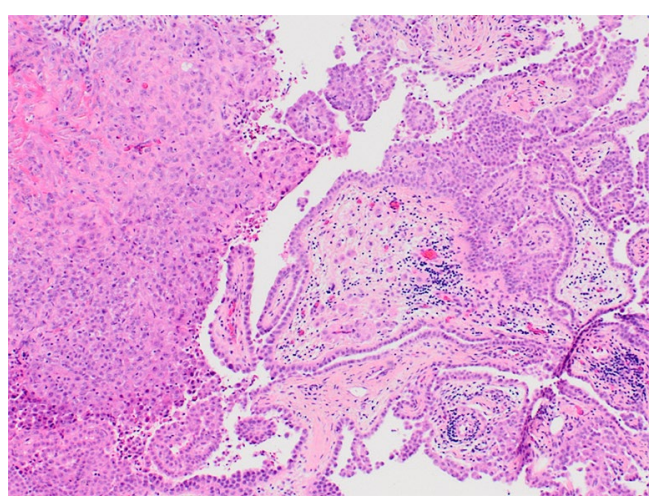

Figure 1 Epithelioid malignant mesothelioma of peritoneum. There is a solid pattern on the left and a tubulopapillary pattern on the right. Hematoxylin and eosin, $\times 10$.

uncritically to peritoneal lesions $(1,2)$.

\section{Morphology}

Malignant mesothelioma is classified as epithelioid, sarcomatoid or biphasic (3). The epithelioid subtype has the better prognosis and is most likely to respond to cytoreduction and HIPEC (4-9). Stage is also a prognostic factor; lymph node metastases confer a worse prognosis $(7,8)$.

In epithelioid malignant mesothelioma, no validated grading system exists. Features reported to be associated with shorter survival include a solid pattern of growth (Figure 1) and 'minimal invasion' (10-13). However, assessment of features such as these are subject to considerable inter-observer variation (14). A histologic grading system of prognostic significance has been described (15), a topic warranting further investigation.

Most malignant mesotheliomas are diffuse, but on very rare occasions localized malignant mesotheliomas may be encountered $(16,17)$. Localized malignant mesotheliomas are cytologically indistinguishable from the diffuse kind, but they are solitary, well circumscribed and show no evidence of diffuse spread. The prognosis appears good and it has been suggested that complete surgical excision may be curative. However, information about their behavior is scanty on account of their rarity.

Well differentiated papillary mesothelioma is a rare neoplasm with characteristic histologic and genetic features $(18,19)$. It is a distinct entity with a good prognosis and should not be confused with epithelioid malignant mesothelioma showing a tubulopapillary pattern of growth (20).

\section{Mitotic count and ki67 proliferation index}

The proliferation fraction in tumor cells as assessed by immunoexpression of ki67 has been shown to be related to prognosis $(6,7,11,21)$. In a study of 117 patients, the authors found that ki67 $>9 \%$ was associated with a poor response to CRS and HIPEC (7). At the Peritoneal Malignancy Institute, Basingstoke, we take the ki67 proliferation index into account when assessing patients' suitability for surgery (22). Other studies have found that high mitotic count is associated with increased mortality $(5,10,23)$.

\section{Immunoexpression of $p 16$}

Expression of p16 is lost in some cases of malignant mesothelioma, correlating with mutation in its encoding gene, $C D K N 2 A$ (24). Loss of p16 is associated with worse survival (5).

\section{BAP1 mutation}

Mutation in BAP1 is common in malignant mesothelioma and is more frequent in peritoneal than pleural primaries (25). $B A P 1$ mutation leads to loss of BAP1 protein expression in tumor nuclei. In pleural mesothelioma, BAP1 mutation and loss of expression have been associated with improved survival (26), and a paper from France reports similar findings in peritoneal mesothelioma (27). Some patients have a germline mutation in $B A P 1$, and such patients have improved survival compared with sporadic cases (28).

\section{Targeted therapy}

The elucidation of mutations such as those described above raises the prospect of treatments targeted at the abnormalities (29-31). A case in point is $A L K$ rearrangement, which is found in some peritoneal mesotheliomas and tends to occur in younger women without asbestos exposure (32). ALK rearrangements are associated with strong immunoexpression of the encoded protein, anaplastic lymphoma kinase. We have recently seen a patient with a peritoneal mesothelioma harboring abnormal $A L K$ who showed a striking response to the tyrosine kinase inhibitor ceritinib (personal observations).

\section{Multicystic mesothelioma: controversial issues}

Multicystic mesothelioma is a controversial entity. It is 


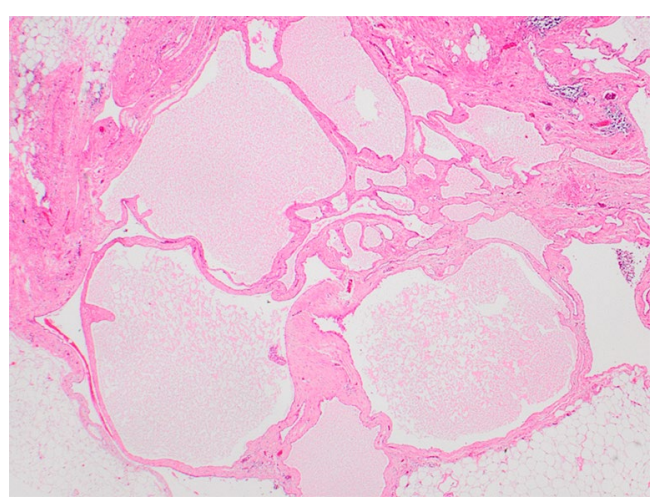

Figure 2 Multicystic mesothelioma of peritoneum. This low power view demonstrates thin-walled cysts of varying size, typical of the neoplasm. Hematoxylin and eosin, $\times 2$.

an uncommon condition that usually affects women of child-bearing age, but there is a wide age range and it also affects men. The most frequent site is the peritoneum of the pelvis and lower abdomen (33-37). No association with asbestos has been documented. Some patients are asymptomatic but others may have abdominal pain which may be related to areas of inflammation or necrosis in the tumor. Histologically, lesions are characterized by cuboidal or flattened mesothelial cells lining thin fibrous walls (Figure 2) $(33,35,38)$.

One controversy is whether multicystic mesothelioma is a true neoplasm. It has been argued that lesions are reactive to chronic irritation and should be designated 'peritoneal inclusion cysts'. However, multicystic mesothelioma can be associated with other neoplasms such as adenomatoid tumor and well differentiated papillary mesothelioma, and it can be progressive and often recurs after surgery (18,33-35,39). Furthermore, lesions have been shown to harbor clonal chromosome abnormalities with fusion transcripts (40). Although it is possible that non-neoplastic mesothelial inclusion cysts could occur as a consequence of inflammation or previous surgery, such lesions are likely to be solitary cysts no more than $5 \mathrm{~mm}$ diameter (33). Multilocular lesions forming a distinct mass should be considered neoplastic.

Another controversial area surrounds management. Given the tendency to recur after surgery, CRS and HIPEC has been recommended, although recurrence even after this treatment has been documented $(33-35,38,41)$. Whether asymptomatic patients should be subjected to such treatment is another question. Rare cases in which there is evidence of progression to malignancy have been reported,

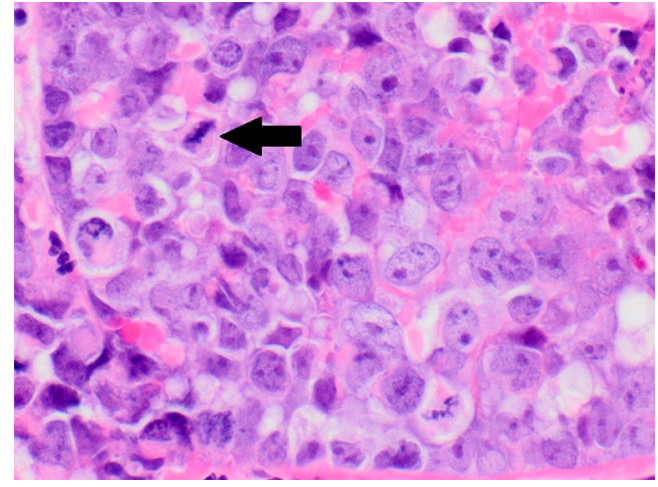

Figure 3 High grade serous carcinoma of the peritoneum. This high power view shows characteristically pleomorphic tumor cells. A mitosis is arrowed. Hematoxylin and eosin, $\times 40$.

but this is also controversial $(42,43)$.

\section{Serous carcinoma involving the peritoneum}

Ovarian epithelial neoplasms are not a single entity but a number of separate tumors with distinctive biological features (44). A consequence is that studies in which these different diseases are combined into a single group for survival analysis may be of limited value. Regarding serous carcinomas in particular, it has become clear that they are of two distinct types: low grade serous carcinoma and high grade serous carcinoma.

\section{High grade serous carcinoma}

It now well established that the vast majority of high grade serous carcinomas arise not from the ovary but from the fallopian tube, in particular from a pre-malignant precursor designated serous tubal intraepithelial carcinoma (STIC) (45). Studies from the era before the significance of STIC was appreciated are likely to have erroneously designated the ovary or peritoneum as the primary site because STIC was not sought or identified. Nevertheless, it is likely that primary peritoneal high grade serous carcinoma, although rare, could exist, possibly arising from implanted tubal epithelium. The 2014 FIGO staging classification allows for this possibility by having fallopian tube, ovarian, "tubo-ovarian" and peritoneal primary sites (46).

Histologically, high grade serous carcinomas are characterized by papillary and solid growth of pleomorphic cells with prominent nucleoli (Figure 3). Over-expression of p53 and p16 is common. The principal means of distinction 


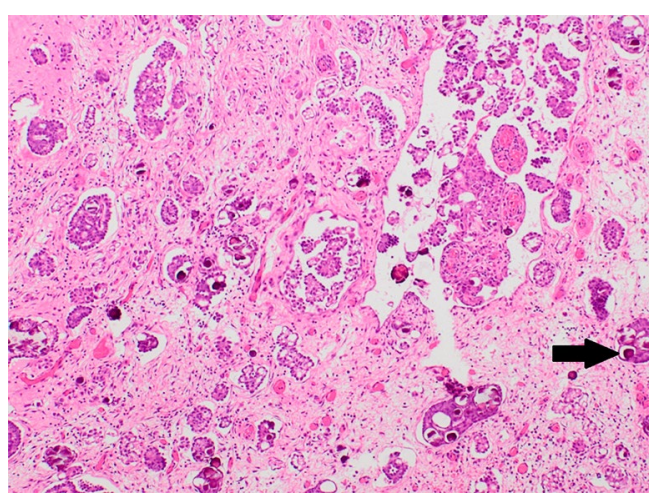

Figure 4 Low grade serous carcinoma of the peritoneum. There are papillae, nests and cribriform structures. Numerous psammoma bodies are present (arrow). Hematoxylin and eosin, $\times 10$.

from low grade serous carcinoma is the degree of cytologic atypia (44).

High-grade serous carcinoma involving the peritoneum may be treated with CRS and HIPEC (47). Improved recognition of the primary site of these lesions and their distinction from other histologic types of 'ovarian' cancer will allow more accurate understanding of how they behave.

\section{Low grade serous carcinoma}

Low grade serous carcinomas are less common than high grade serous carcinomas. They present at a relatively young age and, although relatively resistant to chemotherapy, prolonged survival is usual $(48,49)$. Histologically, low grade serous carcinomas exhibit a complex papillary, micropapillary and/or cribriform architecture, often with psammoma bodies, which may be very numerous (Figure 4). Cytologic atypia is mild or moderate. Unlike high grade tumors, TP53 mutations are generally lacking.

It has been suggested that low grade serous carcinomas develop from serous borderline tumors of the ovary, which are themselves derived from implants of tubal epithelium $(50,51)$. Thus, low grade as well as high grade serous carcinoma is ultimately of tubal origin.

Regarding treatment, our understanding has been restricted by case series that include these neoplasms with other types of ovarian cancer in a 'one size fits all' approach. However studies focussed on low grade serous carcinomas have shown that hormone therapy and CRS have a role in selected cases (52).

\section{Classification of pseudomyxoma peritonei (PMP) and its appendiceal primary tumors}

PMP is a clinical syndrome in which there is progressive accumulation of mucinous material within the peritoneal cavity due to a mucinous neoplasm $(53,54)$. Its distinguishing characteristic is the redistribution phenomenon, whereby the mucin and the neoplastic cells it contains are redistributed through the peritoneal cavity by following the physiological flow of peritoneal fluid to sites of reabsorption, such as the omentum, paracolic gutters and inferior surface of the diaphragm, where the tumor accumulates. Lymphatic and hematogenous metastases are unusual and mostly confined to high grade disease. The vast majority of cases arise from a mucinous tumor of the appendix, but rare primary sites include mucinous tumors of the urachus, pancreas, biliary tract and cervix (55-59). Mucinous tumors arising in mature teratomas of the ovary are also a rare source, as are tailgut cysts $(60,61)$. Rarely, colonic mucinous adenocarcinomas can behave as PMP (62).

Although PMP has been recognised as a neoplastic condition for over a century, its nomenclature has been problematic and the source of considerable controversy, with many different classification systems proposed over the years. One reason is the histologically bland appearance of the mucinous epithelium, despite its malignant behavior (63). For example, Ronnett et al. introduced the term 'adenomucinosis' for well differentiated ('benignlooking') lesions and used the term 'adenoma' for the appendiceal precursors (64). However, alternative terminology of 'mucinous carcinoma peritonei' was proposed by Bradley et al. (65) reflecting the morphologic and behavioral spectrum of PMP, while 'low grade appendiceal mucinous neoplasm' (LAMN) was introduced by Misdraji et al. as an alternative for lesions otherwise termed 'adenoma', 'cystadenoma' or 'mucinous tumor of uncertain malignant potential' (Figure 5) (66).

Given the plethora of contradictory classifications, a modified Delphi process sponsored by the Peritoneal Surface Oncology Group International (PSOGI) was instigated, bringing together international experts in pathology and surgical oncology, including supporters of the principal classification systems then in use. A consensus on terminology was reached, and its use has facilitated comparison of results published by different institutions (54). It also forms the basis of the classification of these lesions in the 2019 World Health Organization (WHO) tumor 
classification $(67,68)$. Table 1 shows the classification of mucinous neoplasms of the appendix; Table 2 shows the classification of PMP.

A detailed analysis of histologic criteria is beyond the scope of this article and readers are referred to recent reviews $(69,70)$. However, there are a number of important points that are worth highlighting.

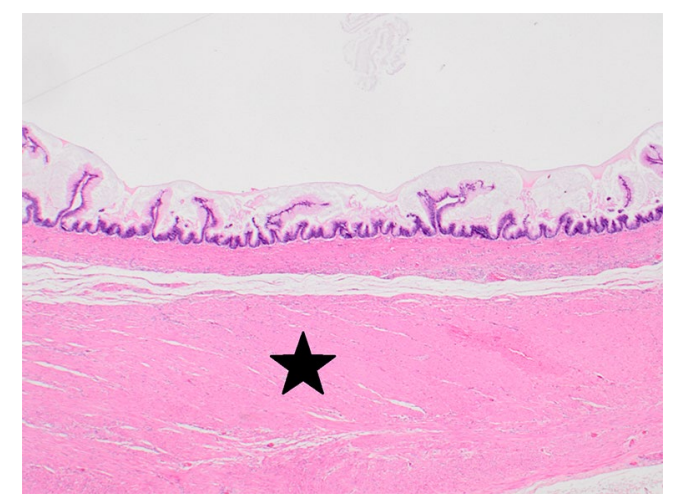

Figure 5 Low grade appendiceal mucinous neoplasm. The neoplastic epithelium shows an undulating pattern with scattered filiform villi. Cytologic atypia is minimal. The muscularis propria is indicated by a star. Hematoxylin and eosin, $\times 4$.
(I) The distinction between 'pushing' and 'infiltrative' invasion is central to the classification (Table 1). Pushing invasion is characterised by broadfront extension into the appendiceal wall that can mimic a diverticulum (Figure 6). It may be associated with dense fibrosis but there is no true desmoplastic reaction. Histologic features of infiltrative invasion include small angulated glands, tumor budding, desmoplasia, and the 'small cellular mucin pool' pattern (Figure 7).

(II) High grade appendiceal mucinous neoplasm (HAMN) is a new entity proposed by the PSOGI consensus for those lesions that do not show infiltrative invasion but have high grade cytology (54). Such lesions had not been previously identified separately, and were designated as either LAMN or adenocarcinoma in previous case series $(66,71,72)$. The limited evidence available suggests they may be more likely to progress to PMP if there is extra-appendiceal mucin at the time of appendectomy (72). They are also more likely to contain TP53 mutations than LAMN (73). Progression of LAMN to HAMN may be associated with activation of the $\mathrm{Wnt} /$ beta-catenin

Table 1 Summary of classification of mucinous appendiceal neoplasms with corresponding WHO grades $(54,67,68)$

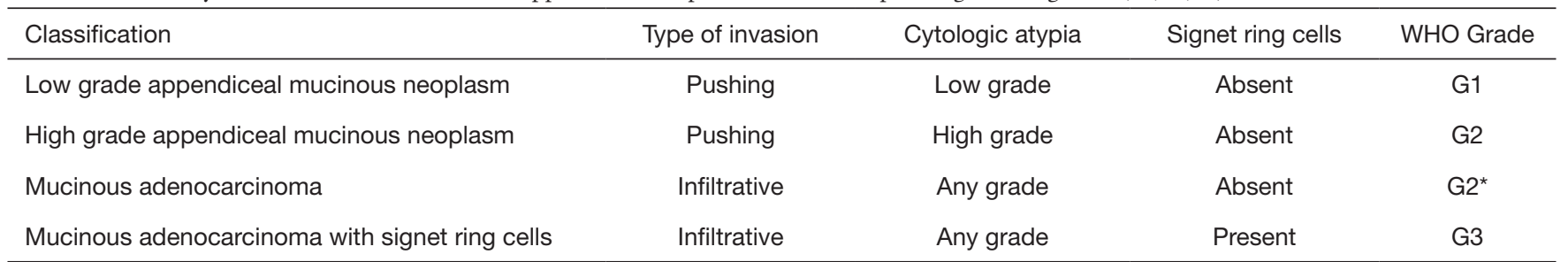

*, rare mucinous adenocarcinomas with sheets of poorly differentiated cells may be designated G3.

Table 2 Diagnostic classification of pseudomyxoma peritonei with corresponding WHO grades (67-69)

\begin{tabular}{lll}
\hline Classification & Typical histologic features & WHO Grade \\
\hline Acellular mucin & $\begin{array}{l}\text { Acellular mucin in the peritoneal cavity without identifiable mucinous } \\
\text { epithelial cells }\end{array}$ & Ungraded \\
Low grade mucinous carcinoma peritonei & Low grade cytologic features, no infiltrative invasion & G1 \\
High grade mucinous carcinoma peritonei & $\begin{array}{l}\text { High-grade cytologic features involving } \geq 10 \% \text { of the tumor, or Infiltrative } \\
\text { invasion }\end{array}$ & G2* \\
High grade mucinous carcinoma peritonei & Mucinous tumor deposits with $\geq 10 \%$ signet ring cells & G3 \\
with signet ring cells & &
\end{tabular}

*, rare cases with sheets of poorly differentiated cells may be designated G3. 


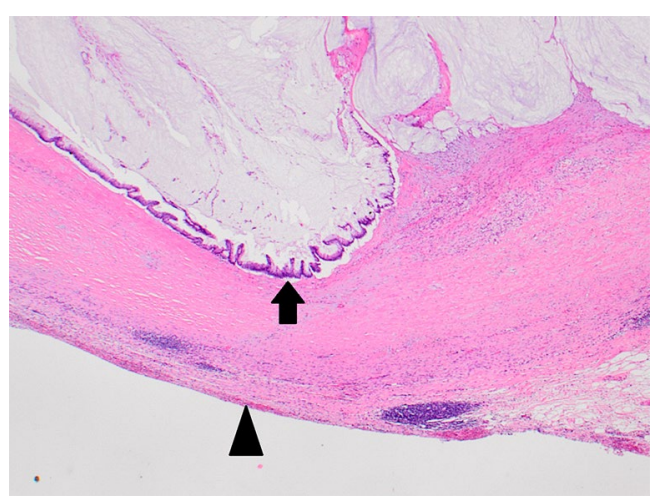

Figure 6 Low grade appendiceal mucinous neoplasm showing pushing invasion. The neoplastic epithelium (arrow) makes a diverticulum-like structure pushing towards the serosal surface (arrowhead). Hematoxylin and eosin, $\times 2$.

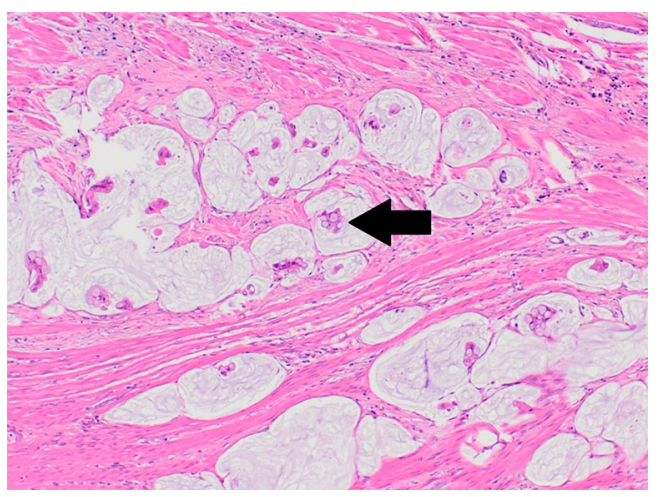

Figure 7 Mucinous adenocarcinoma of appendix, moderately differentiated. The 'small cellular mucin pool' pattern of invasion is visible. Clumps of tumor cells (arrow) surrounded by mucin invade the appendiceal wall. Hematoxylin and eosin, $\times 4$.

pathway (74).

(III) HAMN is staged as adenocarcinoma by the AJCC. Specifically, pT1 and pT2 are used to categorize HAMNs that would be classified $\mathrm{pT}$ Tis (LAMN) if low grade (75). The scanty evidence to date suggests that HAMNs confined to the appendix may have a low risk of progression to PMP (76). If larger studies confirm this finding, it may be better to align the staging of HAMN with LAMN.

(IV) In the appendix, the term 'adenocarcinoma' is reserved for lesions with infiltrative invasion. Although the implication is that they are more likely to spread via lymphatics or bloodstream

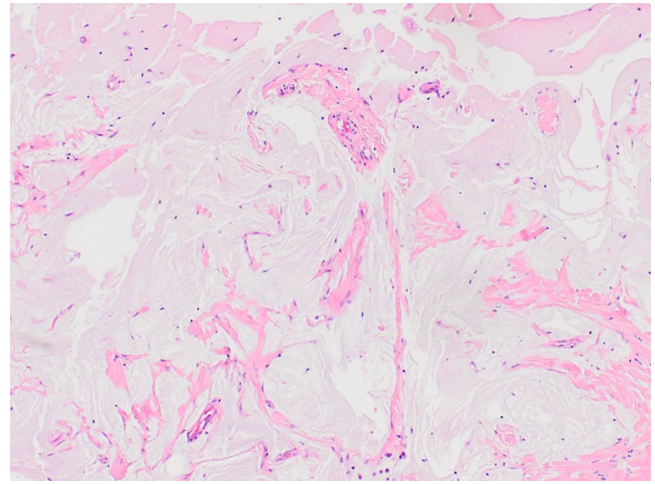

Figure 8 Acellular mucin within the peritoneal cavity derived from a ruptured low grade appendiceal mucinous neoplasm. Hematoxylin and eosin, $\times 4$.

than lesions with pushing invasion, peritoneal metastases are still more common than nodal metastases in patients with appendiceal adenocarcinoma (77).

(V) Lesions with signet ring cells are classified separately because of good evidence they have a worse prognosis (78-81). Since it is sometimes difficult to distinguish degenerating cells in mucin pools from true signet ring cells, it has been suggested that at least $10 \%$ of the cells in PMP should show signet ring morphology before classifying a lesion as such (78).

(VI) Although the grade of the appendiceal primary and the peritoneal disease is usually the same, on rare occasions it may differ. Such cases are said to exhibit discordant histology $(62,64)$.

(VII) The classification shown in Table 2 is prognostically significant (82). Of particular note, if no neoplastic epithelial cells are found histologically despite reasonable sampling, the risk of progressive disease is low (Figure 8) (81,83-85).

\section{Novel avenues of research into PMP}

\section{The pseudomyxoma microbiome}

There is a highly conserved population of bacteria within PMP tissue, including some that are potentially pathogenic, and a greater density of bacteria is found in high grade than low grade PMP $(86,87)$. Antibiotics not only decrease the density of bacteria but also affect beta-catenin expression within the tumor cells (88). Furthermore, some of the 


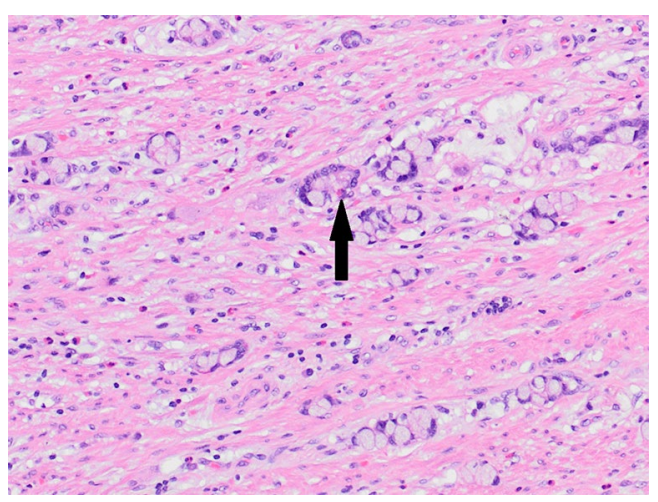

Figure 9 Goblet cell adenocarcinoma. This lesion shows the typical nests of cells (group A in the Tang classification). Rare neuroendocrine cells with red granular cytoplasm are present (arrow). Hematoxylin and eosin, $\times 10$.

bacteria could interact with the mucin, and in one study levels of bacterial 16s ribosomal RNA were directly correlated with MUC2 expression (87). These findings have not yet led to the publication of clinical trials. Treatment with antibiotics is straightforward, relatively low-risk and inexpensive. Perhaps it is time to investigate the potential role of antibiotics in more detail.

\section{New molecular biomarkers of prognosis}

The need for biomarkers to help guide patient management is clear, but we cannot simply extrapolate from colorectal cancer since there are many important differences in the oncogenesis, pathology and behavior of colorectal and appendiceal neoplasms $(89,90)$. For example, in appendiceal mucinous neoplasms KRAS mutations are found in the great majority, GNAS mutations are common, and BRAF mutations are rare. Individual case series of patients with PMP found prognosis was related to immunoexpression of p53, carbonic anhydrase II and SMAD4 (91-93), and gene expression profiling has been used to identify gene clusters of prognostic significance (94). None of these studies has yet led to the introduction of such techniques into general clinical practice, and more research is required.

\section{Organoid models}

Organoid culture allows cells to be grown in an environment that mimics their physiological niche in vivo (95). They represent a means of investigating genetic and epigenetic mechanisms underlying the neoplastic phenotype, and can be used for drug discovery. Their use in PMP has been limited so far, but the creation of organoids from peritoneal metastases of appendiceal neoplasms has been validated (96). A study using organoids derived from primary mucinous appendiceal adenocarcinomas showed that MUC2 expression could be reduced by celecoxib, an action mediated by reduced binding of CREB transcription factor to the MUC2 promotor (97).

\section{Goblet cell adenocarcinoma}

Goblet cell adenocarcinomas are rare neoplasms that are almost always primary in the appendix. They have distinctive morphology and are characterized by tight clusters of cells, sometimes with a small lumen (98-100). Most of the cells have mucin-filled cytoplasm that compresses the nucleus against the peripheral cytoplasmic membrane, but scattered among them small numbers of cells showing neuroendocrine features can usually be found (Figure 9). Common metastatic sites are peritoneum, omentum and ovaries (101).

These lesions were called 'goblet cell carcinoid' for many years, an ambiguous name that has caused them to be confused with neuroendocrine tumors, whereas in fact they are a type of adenocarcinoma. The 5 th edition of the WHO classification now designates them 'goblet cell adenocarcinoma', reflecting their true nature, and 'goblet cell carcinoid' is not recommended (102). They are staged as adenocarcinomas by the AJCC (75).

The behavior of goblet cell adenocarcinomas is related to histologic features. The first published description of a grading system was by Burke et al. (98) and dates from 1990, but a number of others have been published since. The Tang classification divides goblet cell adenocarcinomas into three groups: group A has classical histologic features and the best prognosis; group B shows discohesive growth, increased atypia, irregular clustering and/or desmoplasia and has an intermediate prognosis; group $\mathrm{C}$ is characterized by poorly differentiated features and has the worst prognosis (101). Others have described two-tier grading systems that may be less prone to inter-observer variation than the Tang system $(100,103)$. Taggart et al. described a grading system based on the proportion of tumor showing adverse histologic features reminiscent of the system of Burke et al. (104). A three-tier grading system based on the percentage of tumor showing tubular morphology has also been suggested (105).

None these grading methods has achieved universal 
acceptance. More research into prognostic value and interobserver reproducibility is required (106). The scanty evidence regarding ki67 proliferation index suggests it does not have a role in predicting behavior (107).

The genetic profile of goblet cell adenocarcinomas is strikingly different from that of appendiceal mucinous neoplasms or colorectal adenocarcinoma. Mutations in KRAS, APC, SMAD4 and BRAF are rare (108-111). Abnormalities in genes encoding the Wnt signaling pathway such as USP9X, NOTCH1, CTNNA1, CTNNB1 and TRRAP have been identified (108). These findings are potentially significant in the choice of chemotherapy.

Regarding treatment, recommendations are based on the results of small series and cannot be considered definitive $(112,113)$. Patients with Stage I disease have good survival and can probably be treated with appendectomy alone if the margins are clear, but even this is an uncertain point (114).

\section{Colorectal peritoneal metastases}

The colorectum is the commonest primary site for peritoneal metastasis (115). Pathologic features associated with an increased frequency of peritoneal disease in colorectal adenocarcinoma are mucinous histology, poor differentiation, pT4 status and nodal metastases (116-118). Ovarian involvement is common in women with peritoneal carcinomatosis of colorectal origin, even if the ovaries appear normal macroscopically (119). Although peritoneal carcinomatosis was traditionally associated with a uniformly dismal prognosis, the introduction of radical therapy such as CRS and HIPEC has improved outcome in selected cases (120). This approach is consistent with the fact that in up to $25 \%$ of patients with peritoneal metastases there are no other clinically apparent sites of metastatic spread (121).

Signet ring cells and mucinous histology are associated with decreased survival in patients treated by CRS and HIPEC (122). Survival may also be reduced if free cancer cells are found in cytologic specimens of peritoneal fluid (123).

There are numerous molecular markers associated with peritoneal metastasis (121). A few have been investigated as potential prognostic or predictive factors, or targets for therapy. Angiogenesis plays an important part in the growth of metastatic tumor deposits, and in one study multivariate analysis showed that overall survival after CRS and HIPEC was negatively correlated with high expression of vascular endothelial growth factor (VEGF) (124). Another study found that loss of expression of the stem cell marker CD133 was associated with reduced disease-free survival although the benefit of chemotherapy appeared to be greater (125). Interestingly, although microsatellite instability is generally associated with worse prognosis in patients with nodal or solid organ deposits, it is associated with a better prognosis if peritoneal disease is dominant $(121,126)$.

\section{Conclusions}

A common theme running through this article has been the importance of conceptualizing peritoneal malignancies as distinct pathological conditions rather than extrapolating from other types of neoplasm. For example, PMP is different from other types of mucinous neoplasia, and primary peritoneal mesothelioma shows some important differences from pleural primaries. Another theme has been the relative paucity of data available for the neoplasms discussed. Compared with more common tumors, we know relatively little about the basic biology and optimum management strategies for peritoneal malignancies. The answer is more research; the prize will include not only improvements in patient management but also insights into the biology of neoplastic growth and spread in general.

However, the benefits of research are only maximized if workers use common terminology allowing the results from different institutions to be compared. In the field of appendiceal neoplasia and mucinous carcinoma peritonei, the WHO Classification represents the way forward in this respect. We also need to apply insights from previous work to future research. For example, there can be no excuse for designing a project that looks at 'ovarian cancer' as a single entity when we know that there are different types of ovarian neoplasm that can be classified histologically, have distinctive genetic abnormalities and behave differently.

\section{Acknowledgments}

Funding: None.

\section{Footnote}

Provenance and Peer Review: This article was commissioned by the Guest Editors (Paul H. Sugarbaker and Kurt Van der Speeten) for the focused issue "Intraperitoneal Chemotherapy for Peritoneal Metastases: HIPEC, EPIC, NIPEC, PIPAC and More" published in Fournal of Gastrointestinal Oncology. This article has undergone external peer review. 
Conflicts of Interest: The author has completed the ICMJE uniform disclosure form (available at http://dx.doi. org/10.21037/jgo-2020-01). The focused issue was sponsored by the Peritoneal Surface Oncology Group International (PSOGI). The author has no other conflicts of interest to declare.

Ethical Statement: The author is accountable for all aspects of the work in ensuring that questions related to the accuracy or integrity of any part of the work are appropriately investigated and resolved.

Open Access Statement: This is an Open Access article distributed in accordance with the Creative Commons Attribution-NonCommercial-NoDerivs 4.0 International License (CC BY-NC-ND 4.0), which permits the noncommercial replication and distribution of the article with the strict proviso that no changes or edits are made and the original work is properly cited (including links to both the formal publication through the relevant DOI and the license). See: https://creativecommons.org/licenses/by-nc-nd/4.0/.

\section{References}

1. Borczuk AC, Pei J, Taub RN, et al. Genome-wide analysis of abdominal and pleural malignant mesothelioma with DNA arrays reveals both common and distinct regions of copy number alteration. Cancer Biol Ther 2016;17:328-35.

2. Dragon J, Thompson J, MacPherson M, et al. Differential susceptibility of human pleural and peritoneal mesothelial cells to asbestos exposure. J Cell Biochem 2015;116:1540-52.

3. Churg A, Attanoos R, Borczuk AC, et al. Dataset for reporting of malignant mesothelioma of the pleura or peritoneum: recommendations from the International Collaboration on Cancer Reporting (ICCR). Arch Pathol Lab Med 2016;140:1104-10.

4. Amin W, Linkov F, Landsittel DP, et al. Factors influencing malignant mesothelioma survival: a retrospective review of the National Mesothelioma Virtual Bank cohort. F1000Res 2018;7:1184.

5. Borczuk AC, Taub RN, Hesdorffer M, et al. P16 loss and mitotic activity predict poor survival in patients with peritoneal malignant mesothelioma. Clin Cancer Res 2005;11:3303-8.

6. Kusamura S, Torres Mesa PA, Cabras A, et al. The role of ki-67 and pre-cytoreduction parameters in selecting diffuse malignant peritoneal mesothelioma (DMPM) patients for cytoreductive surgery (CRS) and hyperthermic intraperitoneal chemotherapy (HIPEC). Ann Surg Oncol 2016;23:1468-73.

7. Baratti D, Kusamura S, Cabras AD, et al. Diffuse malignant peritoneal mesothelioma: long-term survival with complete cytoreductive surgery followed by hyperthermic intraperitoneal chemotherapy (HIPEC). Eur J Cancer 2013;49:3140-8.

8. Yan TD, Deraco M, Elias D, et al. A novel tumor-nodemetastasis (TNM) staging system of diffuse malignant peritoneal mesothelioma using outcome analysis of a multi-institutional database. Cancer 2011;117:1855-63.

9. Yonemura Y, Canbay E, Wakama S, et al. Prognostic factors of malignant peritoneal mesothelioma experienced in Japanese peritoneal metastasis center. Gan To Kagaku Ryoho 2019;46:395-9.

10. Krasinskas AM, Borczuk AC, Hartman DJ, et al. Prognostic significance of morphological growth patterns and mitotic index of epithelioid malignant peritoneal mesothelioma. Histopathology 2016;68:729-37.

11. Gilani SN, Mehta A, Garcia-Fadrique A, et al. Outcomes of cytoreductive surgery with hyperthermic intraperitoneal chemotherapy for peritoneal mesothelioma and predictors of survival. Int J Hyperthermia 2018;34:578-84.

12. Valmary-Degano S, Colpart P, Villeneuve L, et al. Immunohistochemical evaluation of two antibodies against PD-L1 and prognostic significance of PD-L1 expression in epithelioid peritoneal malignant mesothelioma: A RENAPE study. Eur J Surg Oncol 2017;43:1915-23.

13. Liu S, Staats P, Lee M, et al. Diffuse mesothelioma of the peritoneum: correlation between histological and clinical parameters and survival in 73 patients. Pathology 2014;46: 604-9.

14. Hartman DJ, Borczuk A, Dacic S, et al. Reproducibility for histologic parameters in peritoneal mesothelioma. Hum Pathol 2017;67:54-9.

15. Valente K, Blackham AU, Levine E, et al. A histomorphologic grading system that predicts overall survival in diffuse malignant peritoneal mesothelioma with epithelioid subtype. Am J Surg Pathol 2016;40:1243-8.

16. Allen TC, Cagle PT, Churg AM, et al. Localized malignant mesothelioma. Am J Surg Pathol 2005;29:866-73.

17. Goldblum J, Hart WR. Localized and diffuse mesotheliomas of the genital tract and peritoneum in women. A clinicopathologic study of nineteen true mesothelial neoplasms, other than adenomatoid tumors, multicystic mesotheliomas, and localized fibrous tumors. Am J Surg Pathol 1995;19:1124-37. 
18. Chen X, Sheng W, Wang J. Well-differentiated papillary mesothelioma: a clinicopathological and immunohistochemical study of 18 cases with additional observation. Histopathology 2013;62:805-13.

19. Stevers M, Rabban JT, Garg K, et al. Well-differentiated papillary mesothelioma of the peritoneum is genetically defined by mutually exclusive mutations of TRAF7 and CDC42. Mod Pathol 2019;32:88-99.

20. Vogin G, Hettal L, Vignaud JM, et al. Well-differentiated papillary mesothelioma of the peritoneum: a retrospective study from the RENAPE Observational Registry. Ann Surg Oncol 2019;26:852-60.

21. Pillai K, Pourgholami MH, Chua TC, et al. Prognostic significance of Ki67 expression in malignant peritoneal mesothelioma. Am J Clin Oncol 2015;38:388-94.

22. Brandl A, Westbrook S, Nunn S, et al. Clinical and surgical outcomes of patients with peritoneal mesothelioma discussed at a monthly national multidisciplinary team video-conference meeting. BJS Open 2020;4:260-7.

23. Scattone A, Serio G, Marzullo A, et al. High Wilms' tumour gene (WT1) expression and low mitotic count are independent predictors of survival in diffuse peritoneal mesothelioma. Histopathology 2012;60:472-81.

24. Krasinskas AM, Bartlett DL, Cieply K, et al. CDKN2A and MTAP deletions in peritoneal mesotheliomas are correlated with loss of $\mathrm{p} 16$ protein expression and poor survival. Mod Pathol 2010;23:531-8.

25. Joseph NM, Chen YY, Nasr A, et al. Genomic profiling of malignant peritoneal mesothelioma reveals recurrent alterations in epigenetic regulatory genes BAP1, SETD2, and DDX3X. Mod Pathol 2017;30:246-54.

26. Brevet $M$. Comparative genetics of diffuse malignant mesothelioma tumors of the peritoneum and pleura, with focus on BAP1 expression. Pleura Peritoneum 2016;1:91-7.

27. Leblay N, Leprêtre F, Le Stang N, et al. BAP1 is altered by copy number loss, mutation, and/or loss of protein expression in more than $70 \%$ of malignant peritoneal mesotheliomas. J Thorac Oncol 2017;12:724-33.

28. Baumann F, Flores E, Napolitano A, et al. Mesothelioma patients with germline BAP1 mutations have 7-fold improved long-term survival. Carcinogenesis 2015;36:76-81.

29. Lai J, Zhou Z, Tang XJ, et al. A tumor-specific neoantigen caused by a frameshift mutation in BAP1 is a potential personalized biomarker in malignant peritoneal mesothelioma. Int J Mol Sci 2016;17:739.

30. Shrestha R, Nabavi N, Lin YY, et al. BAP1 haploinsufficiency predicts a distinct immunogenic class of malignant peritoneal mesothelioma. Genome Med
2019;11:8.

31. Ugurluer G, Chang K, Gamez ME, et al. Genomebased mutational analysis by next generation sequencing in patients with malignant pleural and peritoneal mesothelioma. Anticancer Res 2016;36:2331-8.

32. Hung YP, Dong F, Watkins JC, et al. Identification of ALK rearrangements in malignant peritoneal mesothelioma. JAMA Oncol 2018;4:235-8.

33. Weiss SW, Tavassoli FA. Multicystic mesothelioma: an analysis of pathologic findings and biologic behaviour in 37 cases. Am J Surg Pathol 1988;12:737-46.

34. Nizri E, Baratti D, Guaglio M, et al. Multicystic mesothelioma: Operative and long-term outcomes with cytoreductive surgery and and hyperthermic intra peritoneal chemotherapy. Eur J Surg Oncol 2018;44:1100-4.

35. Sawh RN, Malpica A, Deavers MT, et al. Benign cystic mesothelioma of the peritoneum: a clinicopathologic study of 17 cases and immunohistochemical analysis of estrogen and progesterone receptor status. Hum Pathol 2003;34:369-74.

36. Chua TC, Yan TD, Deraco M, et al. Multi-institutional experience of diffuse intra-abdominal multicystic peritoneal mesothelioma. Br J Surg 2011;98:60-4.

37. Sethna K, Mohamed F, Marchettini P, et al. Peritoneal cystic mesothelioma: a case series. Tumori 2003;89:31-5.

38. Katsube Y, Mukai K, Silverberg SG. Cystic mesothelioma of the peritoneum : a report of five cases and review of the literature. Cancer 1982;50:1615-22.

39. Chan JK, Fong MH. Composite multicystic mesothelioma and adenomatoid tumour of the uterus: different morphological manifestations of the same process? Histopathology 1996;29:375-7.

40. Panagopoulos I, Gorunova L, Davidson B, et al. Novel TNS3-MAP3K3 and ZFPM2-ELF5 fusion genes identified by RNA sequencing in multicystic mesothelioma with $\mathrm{t}(7 ; 17)(\mathrm{p} 12 ; \mathrm{q} 23)$ and $\mathrm{t}(8 ; 11)(\mathrm{q} 23 ; \mathrm{p} 13)$. Cancer Lett 2015;357:502-9.

41. Baratti D, Vaira M, Kusamura S, et al. Multicystic peritoneal mesothelioma: outcomes and pathobiological features in a multi-institutional series treated by cytoreductive surgery and Hyperthermic Intraperitoneal Chemotherapy (HIPEC). Eur J Surg Oncol 2010;36:1047-53 .

42. González-Moreno S, Yan H, Alcorn KW, et al. Malignant transformation of "benign" cystic mesothelioma of the peritoneum. J Surg Oncol 2002;79:243-51.

43. Mino JS, Monteiro R, Pigalarga R, et al. Diffuse 
malignant epithelioid mesothelioma in a background of benign multicystic peritoneal mesothelioma: a case report and review of the literature. BMJ Case Rep 2014;2014:bcr2013200212.

44. Prat J. Ovarian carcinomas: five distinct diseases with different origins, genetic alterations, and clinicopathological features. Virchows Arch 2012;460:237-49.

45. Singh N, McCluggage WG, Gilks CB. High-grade serous carcinoma of tubo-ovarian origin: recent developments. Histopathology 2017;71:339-56.

46. Mutch DG, Prat J. 2014 FIGO staging for ovarian, fallopian tube and peritoneal cancer. Gynecol Oncol 2014;133:401-4.

47. Bakrin N, Gilly FN, Baratti D, et al. Primary peritoneal serous carcinoma treated by cytoreductive surgery combined with hyperthermic intraperitoneal chemotherapy. A multi-institutional study of 36 patients. Eur J Surg Oncol 2013;39:742-7.

48. Longacre TA. Benign and low grade serous epithelial tumors: recent developments and diagnostic problems. Surg Pathol Clin 2011;4:331-73.

49. Hauptmann S, Friedrich K, Redline R, et al. Ovarian borderline tumors in the 2014 WHO classification: evolving concepts and diagnostic criteria. Virchows Arch 2017;470:125-42.

50. Kurman RJ, Vang R, Junge J, et al. Papillary tubal hyperplasia: the putative precursor of ovarian atypical proliferative (borderline) serous tumours, noninvasive implants, and endosalpingiosis. Am J Surg Pathol 2011;35:1605-14.

51. Vang R, Shih IM, Kurman RJ. Fallopian tube precursors of ovarian low- and high-grade serous neoplasms. Histopathology 2013;62:44-58.

52. Fader AN, Bergstrom J, Jernigan A, et al. Primary cytoreductive surgery and adjuvant hormonal monotherapy in women with advanced low-grade serous ovarian carcinoma: Reducing overtreatment without compromising survival? Gynecol Oncol 2017;147:85-91.

53. Järvinen P, Lepistö A. Clinical presentation of pseudomyxoma peritonei. Scand J Surg 2010;99:213-6.

54. Carr NJ, Cecil TD, Mohamed F, et al. A consensus for classification and pathologic reporting of pseudomyxoma peritonei and associated appendiceal neoplasia. Am J Surg Pathol 2016;40:14-26.

55. Delhorme JB, Severac F, Averous G, et al. Cytoreductive surgery and hyperthermic intraperitoneal chemotherapy for pseudomyxoma peritonei of appendicular and extra- appendicular origin. Br J Surg 2018;105:668-76 .

56. Martínez A, Ferron G, Mery E, et al. Peritoneal pseudomyxoma arising from the urachus. Surg Oncol 2012;21:1-5.

57. Jhuang JY, Hsieh MS. Pseudomyxoma peritonei (mucinous carcinoma peritonei) preceded by intraductal papillary neoplasm of the bile duct. Hum Pathol 2012;43:1148-52.

58. Rosenberger LH, Stein LH, Witkiewicz AK, et al. Intraductal papillary mucinous neoplasm (IPMN) with extra-pancreatic mucin: a case series and review of the literature. J Gastrointest Surg 2012;16:762-70.

59. Sugarbaker PH, Rangole AK, Carr NJ. Peritoneal metastases from mucinous endocervical adenocarcinoma. Gynecol Oncol Rep 2014;10:5-8.

60. Zappa L, Godwin TA, Sugarbaker PH. Tailgut cyst, an unusual cause of pseudomyxoma peritonei. Tumori 2009;95:514-7.

61. Vang R, Gown AM, Zhao C, et al. Ovarian mucinous tumors associated with mature cystic teratomas: morphologic and immunohistochemical analysis identifies a subset of potential teratomatous origin that shares features of lower gastrointestinal tract mucinous tumors more commonly encountered as secondary tumors in the ovary. Am. J. Surg. Pathol 2007;31:854-69.

62. Carr NJ, Finch J, Ilesley IC, et al. Pathology and prognosis in pseudomyxoma peritonei: a review of 274 cases. J. Clin. Pathol 2012;65:919-23.

63. Bradley RF, Carr NJ. Pseudomyxoma peritonei: pathology, a historical overview, and proposal for unified nomenclature and updated grading. AJSP Rev Rep 2019;24:88-93.

64. Ronnett BM, Zahn CM, Kurman RJ, et al. Disseminated peritoneal adenomucinosis and peritoneal mucinous carcinomatosis. A clinicopathologic analysis of 109 cases with emphasis on distinguishing pathologic features, site of origin, prognosis, and relationship to "pseudomyxoma peritonei". Am J Surg Pathol 1995;19:1390-408.

65. Bradley RF, Stewart JH, Russell GB, et al. Pseudomyxoma peritonei of appendiceal origin: a clinicopathologic analysis of 101 patients uniformly treated at a single institution, with literature review. Am J Surg Pathol 2006;30:551-9.

66. Misdraji J, Yantiss RK, Graeme-Cook FM, et al. Appendiceal mucinous neoplasms: a clinicopathologic analysis of 107 cases. Am J Surg Pathol 2003;27:1089-103.

67. Misdraji J, Carr NJ, Pai RK. Appendiceal mucinous neoplasm. In: WHO Classification of Tumours Editorial Board. Digestive System Tumours. Lyon: IARC, 2019:144-6. 
68. Misdraji J, Carr NJ, Pai RK. Appendiceal adenocarcinoma. In: WHO Classification of Tumours Editorial Board. Digestive System Tumours. Lyon: IARC, 2019147-8.

69. Valasek MA, Pai RK. An update on the diagnosis, grading and staging of appendiceal mucinous neoplasms. Adv Anat Pathol 2018;25:38-60.

70. Carr NJ, Bibeau F, Bradley RF, et al. The histopathological classification, diagnosis and differential diagnosis of mucinous appendiceal neoplasms, appendiceal adenocarcinomas and pseudomyxoma peritonei. Histopathology 2017;71:847-58.

71. Pai RK, Beck AH, Norton JA, et al. Appendiceal mucinous neoplasms: clinicopathologic study of 116 cases with analysis of factors predicting recurrence. Am J Surg Pathol 2009;33;1425-39.

72. Yantiss RK, Shia J, Klimstra DS, et al. Prognostic significance of localized extra-appendiceal mucin deposition in appendiceal mucinous neoplasms. Am J Surg Pathol 2009;33:248-55.

73. Liao X, Vavinskaya V, Sun K, et al. Mutation profile of high-grade appendiceal mucinous neoplasm. Histopathology 2020;76:461-9.

74. Tsai JH, Yang CY, Yuan RH. Correlation of molecular and morphological features of appendiceal epithelial neoplasms. Histopathology 2019;75:468-77.

75. Overman MJ, Asare EA, Compton CC, et al. Appendix carcinoma. In: Amin MB. editor. AJCC Cancer Staging Manual, Eighth Edition. Chicago: AJCC, 2017:237-50.

76. Singhal S, Giner-Segura F, Barnes TG, et al. The value of grading dysplasia in appendiceal mucinous neoplasm in the absence of pseudomyxoma peritonei. Histopathology 2018;73:351-4.

77. Mehta A, Mittal R, Chandrakumaran K, et al. Peritoneal involvement is more common than nodal involvement in patients with high-grade appendix tumors who are undergoing prophylactic cytoreductive surgery and hyperthermic intraperitoneal chemotherapy. Dis Colon Rectum 2017;60:1155-61.

78. Davison JM, Choudry HA, Pingpank JF, et al. Clinicopathologic and molecular analysis of disseminated appendiceal mucinous neoplasms: identification of factors predicting survival and proposed criteria for a three-tiered assessment of tumor grade. Mod. Pathol 2014;27:1521-39.

79. Shetty S, Natarajan B, Thomas P, et al. Proposed classification of pseudomyxoma peritonei: influence of signet ring cells on survival. Am Surg 2013;79:1171-6.

80. Sirintrapun SJ, Blackham AU, Russell G, et al. Significance of signet ring cells in high-grade mucinous adenocarcinoma of the peritoneum from appendiceal origin. Hum Pathol 2014;45:1597-604.

81. Baratti D, Kusamura S, Milione M, et al. Validation of the recent PSOGI pathological classification of pseudomyxoma peritonei in a single-center series of 265 patients treated by cytoreductive surgery and hyperthermic intraperitoneal chemotherapy. Ann Surg Oncol 2018;25:404-13.

82. Huang Y, Alzahrani NA, Chua TC, et al. Histological subtype remains a significant prognostic factor for survival outcomes in patients with appendiceal mucinous neoplasm with peritoneal dissemination. Dis Colon Rectum 2017;60:360-7.

83. Carr NJ, McCarthy WF, Sobin LH. Epithelial noncarcinoid tumors and tumor-like lesions of the appendix: a clinicopathologic study of 184 patients with a multivariate analysis of prognostic factors. Cancer 1995;75:757-68.

84. Roxburgh CS, Fenig YM, Cercek A, et al. Outcomes of low-grade appendiceal mucinous neoplasms with remote acellular mucinous peritoneal deposits. Ann Surg Oncol 2019;26:118-24.

85. Choudry HA, Pai RK, Shuai Y, et al. Impact of cellularity on oncologic outcomes following cytoreductive surgery and hyperthermic intraperitoneal chemoperfusion for pseudomyxoma peritonei. Ann Surg Oncol 2018;25:76-82.

86. Gilbreath JJ, Semino-Mora C, Friedline CJ, et al. A core microbiome associated with the peritoneal tumors of pseudomyxoma peritonei. Orphanet J Rare Dis 2013;8:105.

87. Semino-Mora C, Liu H, McAvoy T, et al. Pseudomyxoma peritonei: is disease progression related to microbial agents? A study of bacteria, MUC2 AND MUC5AC expression in disseminated peritoneal adenomucinosis and peritoneal mucinous carcinomatosis. Ann Surg Oncol 2008;15:1414-23.

88. Semino-Mora C, Testerman TL, Liu H, et al. Antibiotic treatment decreases microbial burden associated with pseudomyxoma peritonei and affects -catenin distribution. Clin Cancer Res 2013;19:3966-76.

89. Raghav KP, Shetty AV, Kazmi SM, et al. Impact of molecular alterations and targeted therapy in appendiceal adenocarcinomas. Oncologist 2013;18:1270-7.

90. Levine EA, Blazer DG, Kim MK, et al. Gene expression profiling of peritoneal metastases from appendiceal and colon cancer demonstrates unique biologic signatures and predicts patient outcomes. J Am Coll Surg 2012;214:599-606.

91. Shetty S, Thomas P, Ramanan B, et al. Kras mutations and $\mathrm{p} 53$ overexpression in pseudomyxoma peritonei: 
association with phenotype and prognosis. J Surg Res 2013;180:97-103.

92. Järvinen P, Kivelä AJ, Nummela P, et al. Carbonic anhydrase II: a novel biomarker for pseudomyxoma peritonei. APMIS 2017;125:207-12.

93. Davison JM, Hartman DA, Singhi AD, et al. Loss of SMAD4 protein expression is associated with high tumor grade and poor prognosis in disseminated appendiceal mucinous neoplasms. Am J Surg Pathol 2014;38:583-92.

94. Levine EA, Votanopoulos KI, Qasem SA, et al. Prognostic molecular subtypes of low-grade cancer of the appendix. J Am Coll Surg 2016;222:493-503.

95. Maru Y, Onuma K, Ochiai M, et al. Shortcuts to intestinal carcinogenesis by genetic engineering in organoids. Cancer Sci 2019;110:858-66.

96. Votanopoulos KI, Mazzocchi A, Sivakumar H, et al. Appendiceal cancer patient-specific tumor organoid model for predicting chemotherapy efficacy prior to initiation of treatment: a feasibility study. Ann Surg Oncol 2019;26:139-47.

97. Dilly AK, Honick BD, Lee YJ, et al. Targeting G-protein coupled receptor-related signaling pathway in a murine xenograft model of appendiceal pseudomyxoma peritonei. Oncotarget 2017;8:106888-900.

98. Burke AP, Sobin LH, Federspiel BH, et al. Goblet cell carcinoids and related tumors of the vermiform appendix. Am J Clin Pathol 1990;94:27-35.

99. van Eeden S, Offerhaus GJ, Hart AA, et al. Goblet cell carcinoid of the appendix: a specific type of carcinoma. Histopathology 2007;51:763-73.

100. Nonaka D, Papaxoinis G, Lamarca A, et al. A study of appendiceal crypt cell adenocarcinoma (so-called goblet cell carcinoid and its related adenocarcinoma). Hum Pathol 2018;72:18-27.

101. Tang LH, Shia J, Soslow RA, et al. Pathologic classification and clinical behavior of the spectrum of goblet cell carcinoid tumors of the appendix. Am J Surg Pathol 2008;32:1429-43.

102.Misdraji J, Carr NJ, Pai RK. Appendiceal goblet cell adenocarcinoma. In: WHO Classification of Tumours Editorial Board. Digestive System Tumours. Lyon: IARC, 2019:149-151.

103.Lee LH, McConnell YJ, Tsang E, et al. Simplified 2-tier histologic grading system accurately predicts outcomes in goblet cell carcinoid of the appendix. Hum Pathol 2015 46;1881-9.

104. Taggart MW, Abraham SC, Overman MJ, et al. Goblet cell carcinoid tumor, mixed goblet cell carcinoid- adenocarcinoma, and adenocarcinoma of the appendix: comparison of clinicopathologic features and prognosis. Arch Pathol Lab Med 2015;139:782-90.

105. Yozu M, Johncilla ME, Srivastava A, et al. Histologic and outcome study supports reclassifying appendiceal goblet cell carcinoids as goblet cell adenocarcinomas, and grading and staging similarly to colonic adenocarcinomas. Am J Surg Pathol 2018;42:898-910.

106. Maedler C, Arnason T, Dorreen A, et al. Goblet cell carcinoid of the appendix - an interobserver variability study using two proposed classification systems. Ann Diagn Pathol 2018;32:51-5.

107.Liu E, Telem DA, Warner RR, et al. The role of ki-67 in predicting biological behavior of goblet cell carcinoid of the appendix. Am J Surg 2011;202:400-3.

108. Jesinghaus M, Konukiewitz B, Foersch S, et al. Appendiceal goblet cell carcinoids and adenocarcinomas ex-goblet cell carcinoid are genetically distinct from primary colorectal-type adenocarcinoma of the appendix. Mod Pathol 2018;31:829-39.

109. Dimmler A, Geddert H, Faller G. EGFR, KRAS, BRAFmutations and microsatellite instability are absent in goblet cell carcinoids of the appendix. Pathol Res Pract 2014;210:274-8.

110.Johncilla M, Stachler M, Misdraji J, et al. Mutational landscape of goblet cell carcinoids and adenocarcinoma ex goblet cell carcinoids of the appendix is distinct from typical carcinoids and colorectal adenocarcinomas. Mod Pathol 2018;31:989-996.

111. Wen KW, Grenert JP, Joseph NM, et al. Genomic profile of appendiceal goblet cell carcinoid is distinct compared to appendiceal neuroendocrine tumor and conventional adenocarcinoma. Hum Pathol 2018;77:166-74.

112. Fields AC, Lu P, Enzinger A, et al. Treatment patterns and outcomes in goblet cell carcinoid tumors of the appendix. J Surg Oncol 2019;120:1096-101.

113.Lamarca A, Nonaka D, Lopez Escola C, et al. Appendiceal goblet cell carcinoids: management considerations from a reference peritoneal tumour service centre and ENETS centre of excellence. Neuroendocrinology 2016;103:500-17.

114.Pham TH, Wolff B, Abraham SC, et al. Surgical and chemotherapy treatment outcomes of goblet cell carcinoid: a tertiary cancer center experience. Ann Surg Oncol 2006; 13:370-6 .

115. Solon JG, O'Neill M, Chang KH, et al. An 18 year population-bases study on site of origin and outcome of patients with peritoneal malignancy in Ireland. Eur J Surg 
Oncol 2017;43:1924-31.

116.Lemmens VE, Klaver YL, Verwaal VJ, et al. Predictors of survival of synchronous peritoneal carcinomatosis of colorectal origin: a population-based study. Int J Cancer 2011;128:2717-25.

117. Quere P, Facy O, Manfredi S, et al. Epidemiology, management, and survival of peritoneal carcinomatosis from colorectal cancer: a population-based study. Dis Colon Rectum 2015;58:743-52.

118. Segelman J, Granath F, Holm T, et al. Incidence, prevalence and risk factors for peritoneal carcinomatosis from colorectal cancer. Br J Surg 2012;99:699-705.

119. Mehta AM, Bignell MB, Alves S, et al. Risk of ovarian involvement in advanced colorectal or appendiceal tumors involving the peritoneum. Dis Colon Rectum 2017;60:691-6.

120.Narasimhan V, Britto M, Pham T, et al. Evolution of cytoreductive surgery and hyperthermic intraperitoneal chemotherapy for colorectal peritoneal metastases: 8-year single-institutional experience. Dis Colon Rectum 2019;62:1195-203.

121. Sluiter N, de Cuba E, Kwakman R, et al. Adhesion molecules in peritoneal dissemination: function, prognostic relevance and therapeutic options. Clin Exp Metastasis 2016;33:401-16.

122. Massalou D, Beniziri E, Chevallier A, et al. Peritoneal carcinomatosis of colorectal cancer: novel clinical and molecular outcomes. Am J Surg 2017;213:377-87.

123. Trilling B, Cotte E, Vaudoyer D, et al. Intraperitonealfree cancer cells represent a major prognostic factor in colorectal peritoneal carcinomatosis. Dis Colon Rectum 2016;59:615-22.

124. de Cuba EM, de Hingh IH, Sluiter NR, et al. Angiogenesis-related markers and prognosis after cytoreductive surgery and hyperthermic intraperitoneal chemotherapy for metastatic colorectal cancer. Ann Surg Oncol 2016;23:1601-8.

125.Nagata H, Ishihara S, Kishikawa J, et al. CD113 expression predicts post-operative recurrence in patients with colon cancer with peritoneal metastasis Int J Oncol 2018;52:721-32.

126. Fujiyoshi K, Yamamoto G, Takenoya T, et al. Metastatic pattern of stage IV colorectal cancer with high-frequency microsatellite instability as a prognostic factor. Anticancer Res 2017;37:239-47.
Cite this article as: Carr NJ. New insights in the pathology of peritoneal surface malignancy. J Gastrointest Oncol 2021;12(Suppl 1):S216-S229. doi: 10.21037/jgo-2020-01 